ISSN: 2162-3104 Print/ ISSN: 2166-3750 Online

Volume 8, Issue 1 (2018), pp. 131-150

(C) Journal of International Students

http://jistudents.org/

doi: 10.5281/zenodo.1134269

\title{
Chinese University Students and Their Experiences of Acculturation at an Ethnic Christian Church
}

\author{
Xiaoyang Sun \\ Temple University, United States \\ Robert A. Rhoads \\ University of California Los Angeles, United States
}

\begin{abstract}
This paper examines the experiences of Chinese international students from East Coast University (a pseudonym) in the United States through their participation in a Chinese ethnic-based Christian church (CCC). Employing ethnographic-based fieldwork, the study highlights how Chinese international students see their experiences in CCC as a source of acculturation to U.S. society. However, the students evidence little understanding of the reality that they are in fact being acculturated to a subculture within U.S. society that at times embraces values contradictory to those of progressive-oriented East Coast University.
\end{abstract}

Keywords: acculturation, Chinese international students, diversity mission, ethnographic methods, subculture

Globalization has produced interconnected economies and arguably transformed the world into a self-regulated global entity in which decisions by leading nations such as the United Kingdom and the United States have a powerful effect on other nations (Arrighi, 2010; Polanyi, 2001). As Wallerstein (2004) argued, the world has moved toward a single "world system" with countries categorized as core, semi-peripheral, and peripheral. Although much attention has been given to the economic and political implications of a world system, much less analysis has addressed the 
cultural facets of globalization, including the growing multicultural nature of major cities and regions in countries experiencing high levels of immigration both in terms of temporary and permanent residents (Luke \& Luke, 2000; Sassen, 1991; Smith, 2006). One area where this is clearly having an impact is in higher education and the increasing mobility of students. Chinese students in particular have become a global force in terms of their level of mobility as international students seeking degrees beyond their homeland. And the United States, of course, has become the dominant player as a host country for Chinese international students.

Recent years have witnessed a huge increase in the flow of international students to colleges and universities in the United States. For example, 2015 data from the U.S. Department of Homeland Security revealed that 1.13 million foreign students were studying in the United States; this represents an 85 percent increase from 2005 (Jordan, 2015). Asia is the leading region from which U.S. foreign students come (Ruiz, 2014), with China by far the largest sending nation, accounting for 29 percent (over 330,000 students) of the U.S. international student enrollment (Jordan, 2015). As Williams noted, international students "in pursuit of professional credentials, social capital, and cultural fluency...stimulated the U.S. economy to the tune of 22 billion dollars, making higher education one of the United States' most important service sector exports" (2013, p. 256). With more and more international students from Asian countries such as China coming to the United States, and in light of dramatic cultural differences between East and West, the acculturation of these students should be of central concern to the colleges and universities hosting them.

With the preceding points in mind, this paper explores the experiences of acculturation among Chinese international students at East Coast University (ECU), a pseudonym for a large university near the east coast of the United States. Furthermore, we examine the experiences of Chinese students through their engagement in a local church called Chinese Christian Church (CCC), also a pseudonym. The church is situated adjacent to the ECU campus and has extensive outreach services targeting the needs of Chinese international students. Given the growing numbers of Chinese internationals who come to the United States for academic study, it is important to better understand the nature of their experiences as they seek to adjust to their new environment and surroundings. As global forces continue to act on nations and individual social actors such as college students, more research needs to address this growing phenomenon. Further, research has demonstrated that many Chinese international students become engaged in Christian organizations, but little is known about how such experiences 
contribute to their acculturation to the multicultural nature of U.S. society. Thus, it is necessary to better understand how Chinese college students construct meaning relative to their involvement in campus-oriented Christian organizations such as CCC as part of their broader acculturation to the society. Accordingly, the following research questions guide our study:

1. What explanations do Chinese international students offer in terms of their decision to study abroad and how did they come to select the United States?

2. How do ECU students make sense of their involvement in a Chinese Christian church relative to their experiences in the United States and to what extent does it help with their adjustment to their new environment?

We argue that Chinese international students at ECU get involved in $\mathrm{CCC}$ to access a variety of benefits, but that easing their adjustment or acculturation to U.S. society is a key one. In examining the experiences of Chinese international students at $\mathrm{CCC}$, we make use of concepts and theories related to globalization, multiculturalism, and acculturation, while also relying heavily on the sociological school of thought known as symbolic interactionism (S.I.). Our objective is to better understand how Chinese students make sense of their involvement in CCC as a form of acculturation. Because of our focus on sense making, we argue that S.I. is a good methodology to use, given that it centers the lived experiences of social actors as they interact with and interpret their environments. We also use ethnographic methods as part of our research strategy, as this allows us to engage with Chinese undergraduates at CCC. Ethnography as a method offers sound field-based strategies for digging deeper into the meaning people give to their experiences.

\section{LITERATURE REVIEW}

We organize a discussion of the literature into two parts: (a) a discussion of previous research related to Chinese internationals and their involvement with Christianity, and (b) a discussion of the theoretical influences that we draw on to guide our analysis.

\section{Chinese Internationals and Christianity}

Many scholars in the field of sociology of religion have looked at the issue of religious conversion. What makes this body of literature of 
special importance for our research is that some of these studies examined the conversion to Christianity among Asian Americans, Chinese immigrants, and in some cases, among Chinese international students and scholars.

Assimilation is a key sociological concept often used in examining religious conversion and when looking at motives for converting to Christianity among immigrants. Yang (1998) lays out three assimilation explanations for interpreting immigrant religious conversion. The first explanation Yang described is in terms of "Rice Christians," which relates to the idea that many immigrants join a church in order to gain material help. The motive for getting material benefits from the church comes from their immigrant status, where as members of a new society they have little to no access to resources and key social institutions. The church thus fills the resource-gap void. This instrumental aspect of religious experience among Chinese international students in particular is evidenced in other studies where researchers found that ethnic-oriented evangelical churches tend to make the atmosphere of their churches as friendly and welcoming as possible. Examples of welcoming behaviors include providing dinner, offering airport pickup service, and inviting immigrants to Bible study groups where they might also improve their English. Some religious organizations even work as moral guards by discouraging immigrants from going astray through such habits as smoking, engaging in prostitution, or gambling (Kalir, 2009; Wang \& Yang, 2006; Williams, 2013). Cadge and Ecklund (2007) also suggest that the material support is a key facet to the conversion of immigrants given that "religious organizations facilitate their adaptation in the United States" (p. 362).

A second explanation offered by Yang (1998) is called "Assimilation to the Dominant Culture of the Host Society." This explanation relates to the idea that new immigrants have the urgent desire to assimilate and Christianity is seen as a vehicle for that, because they tend to associate being Christian with being American. In describing how religious participation strengthens the civic life of immigrants, Cadge and Ecklund (2007) supported Yang's argument, when they noted that, "High levels of cultural and religious assimilation were expected to foster large-scale inclusion into the networks and institutions of American civic life" (p. 366).

The last assimilation explanation Yang (1998) lays out is called "Joining the Church to Meet Ethnic Needs," where the social needs for ethnic fellowship and ethnic belonging come into play. In cases where ethnic fellowship is stressed, the religious purpose may be secondary or non-essential. A study done by Cao (2005) illustrates the need for ethnic 
affinity and social relations. In the study of a Cantonese Christian church in New York's Chinatown, he examines the religious experience of working class Chinese youth, arguing that "the Chinatown church plays a Chinese family role and helps people overcome difficulties by rebuilding interpersonal relationships" (p. 190). Further, he concluded that "relationship building is a major concern" of the Cantonese Christian church (p. 190). What is more revealing is that for those working class Chinese youth, not only do they see that relationship building with God matters, but they tend to place even greater importance on relationship building with church members of their same ethnicity. Further research done by Hurh and Kim (1990) on Christian Korean Americans complicated this explanation to some degree, noting that the social, religious, and psychological needs are in fact inseparable and intertwined at times for Korean immigrants.

Other research though further reinforced the idea of the importance of church in promoting ethnicity among immigrants concerned about assimilation (Yang \& Tamney, 2006). Cadge and Ecklund (2007) argued that ethnic churches may be particularly appealing to immigrants because such churches tend to emphasize preserving "ethnic customs, language, and group solidarity" (p. 362), all potentially appealing attributes to immigrant populations. An empirical case is provided in Chong's (1998) study where he found that many second-generation Koreans are aware of the existence of racism and discrimination, and thus they turn to an ethnic church to construct, support, and reinforce their ethnic identify. They see such churches as helping them to compensate for their disadvantaged and marginalized status in mainstream society, mainly through church-related social networks that help them to maintain their culture and language.

Specific concerns have been addressed in studying the broader social and cultural context of conversion to evangelical Christianity among Chinese immigrants. Yang (1998) criticizes the micro-level perspective that merely attributes religious conversion among Chinese immigrants to personal characteristics. Instead, he adopts a broader theoretical lens and argues that social and cultural changes in China, especially in the era of globalization and related to a coerced modernization, are main factors that promote massive conversion to Christianity among Chinese immigrants. To put this another way, due to the dramatic cultural, political, and economic changes in China over the past several decades, the experiences of Chinese immigrants is defined in some sense by turmoil. Thus, when confronted with a new society in the United States, Yang argues that, "Chinese immigrants are both free and bound to seek alternative meaning systems" (p. 253). Yang's argument is also supported by Hall (2006), who argued that the 
collapse of Chinese traditionalism contributes to Chinese students converting to Christianity. He points to dramatic changes in China over the years, including the elimination of many traditions during the Cultural Revolution and then changes due to rapid modernization.

What all of this suggests is that in our efforts to make sense of the experiences of Chinese students at CCC we need to consider a variety of influences and factors in making sense of their experiences. The previous research also points to the need to stress the meaning making of Chinese students and their engagement with religion, particularly as it relates to efforts to acculturate to U.S. society.

\section{Theoretical Perspective}

In developing this study, we relied on key theoretical ideas linked to the concepts of globalization, multiculturalism, and acculturation. Globalization as a broad idea of course undergirds the basic nature of this study in that we seek to make sense of the growing trends in higher education related to students studying abroad. This trend is reflective of what scholars such as Giddens (1990) and Held (1991) see as a globalized world where time and space are both reduced to such an extent that events occurring in one part of the world may have a powerful and immediate impact on other places in the world. In essence, the world has more or less become one interlocked world system (Wallerstein, 2004). This means that industries are often competing not only in local markets, but they must face competitors around the world. Relative to higher education, globalization is seen as defining a more competitive and more tightly connected market place in which colleges and universities around the world compete for students, faculty, and flows of revenue (Altbach, 2003; Rhoads \& Szelényi, 2011; Slaughter \& Rhoades, 2004).

Globalization not only has economic and political effects, but it also operates at a cultural level in what some have described as "cultural globalization" (Luke \& Luke, 2000). This is most evident when one examines the changing nature of major cities such as New York City, London, Tokyo, and Los Angeles and the ways in which urban landscapes have become multicultural in nature (Sassen, 1991; Smith, 2006). The same may be said about broad societies such as the United States, where it is harder and harder to define a core culture and where lived experience is defined less by the societal culture and more the by subcultural experience of particular ethnic groups. The reality of a multicultural U.S. society further complicates studies of assimilation and acculturation in that identifying a 
clear cultural center to which one integrated is rather difficult, a point made clear by Buenker and Ratner (2005) in their study of the challenges of assimilation and ethnic diversity in American society.

Given the role of immigration and the growth of multicultural cities and societies in an age of globalization, it is therefore important to explore theoretical ideas relating to acculturation. By acculturation, we mean the adjustment process involving a "change in individuals whose primary learning has been in one culture and who take over traits from another culture" (Marden \& Meyer, 1968, p. 36). Although many scholars in diverse disciplines have advanced theories of acculturation, we rely mostly on arguments consistent with S.I. and focusing mainly on how the people create meaning and interpret their lived experiences.

A helpful starting point for us is the Thomas Theorem, which argues that if situations are defined as real then they are real in their consequences (Thomas \& Thomas, 1928, p. 572). What this means relative our study of Chinese international students is that it doesn't necessarily matter whether they interpret events accurately or not, because they are going to explain their actions and behaviors on the basis of their interpretations, even when incorrect. Blumer (1962) made a similar point saying that "human beings act toward things on the basis of the meanings which these things have for them" (p. 2). So, our goal from an S.I. perspective is to understand how the students interpret their experiences and create meaning as part of their acculturation to a new society through their involvement at CCC.

Immigration and acculturation have been a point of study for symbolic interactionists dating back to Thomas and Znaniecki's (1919) famous book, The Polish Peasant in Europe and America. More recently, Kang (1971) examined name changes among Chinese international college students using S.I. and Shirpak, Maticka-Tyndale, and Chinichian (2007) examined Iranian immigrants to Canada and how they made sense of sexuality in their new society. What these works share is a focus on the ways in which immigrants create meanings and understandings in their new environment through a variety of social relations and interactive experiences.

In building on Blumer's (1962) basic argument about symbolic interactionism, Kang (1971) argued that a name change among Chinese college students signifies "a change in the matrix of social relations" and that such a change is likely to compel the changer "to remodel his patterns of social behaviors and make them consistent with the changed structure of his new identity" (p. 404). The same way of thinking may be considered when one thinks of Chinese students becoming involved in a new religion or 
with a church representing a new religion. Thus, this aspect of S.I. led us to wonder about how the students' involvement in the church leads to new patterns of social behavior or perhaps new social relations.

From the perspective of Blumer (1962), human beings have a self, meaning that they can be objects of their own action. As Blumer argued, "Thus, he can recognize himself, for instance, as being a man, young in age, a student, in debt, trying to become a doctor, coming from an undistinguished family and so forth. In all such instances he is an object to himself; and he acts toward himself and guides himself in his actions toward others on the basis of the kind of object he is to himself' (p. 12). What this means for the study is that we need to better understand the ways in which the Chinese international students see and think of themselves as objects situated within a new environment and confronted with new social groups and relations (as part of their acculturation), specifically the ones that take place at CCC. Ethnographic methods perhaps offer the best research strategy for developing such insights.

\section{RESEARCH METHOD}

In order to study the participation and experience of Chinese international students in CCC, the lead author spent 18 weeks conducting field-based research in a manner consistent with ethnographic techniques. Conducting ethnographic research is an excellent way to develop a deeper understanding of the meaning making and experiences of Chinese international students. This is supported by the claims of ethnographic researchers who argue that ethnography "directs social researchers to study human society from the points of view of its members" (Gold, 1997, p. 399). By listening to the explanations students offer about their own experiences as well as observing the conversations among students participating in CCC activities, we were able to develop a depth of knowledge about the social context and interpretations of it. Given that participation in CCC is an ongoing process, which may only offer significant interpretations after a period of time, it makes sense to spend time at the field site given that ethnography "is well suited for the study of social processes over time" (Babbie, 2007, p. 287).

The site for this study is of course Chinese Christian church (CCC) serving the Chinese student community at East Coast University (ECU), a large research university near the east coast of the United States. CCC is an ethnic evangelical church whose clergy and staff mostly derive from mainland China and Taiwan. Chinese Mandarin is used by the staff when 
conducting religious services and Bible studies. CCC is located in a section of the city that is mostly low-come and African American and in fact shares the church's physical space with a local African American church. Our interest in studying CCC evolved from the lead author's early participation and then her growing curiosity about the nature of the Chinese students' experiences, including their interpretations of such experiences. Her own identification as Chinese aided in gaining access to the students participating in CCC and also enabled her to "blend in" during participant observation. The lead author's Chinese background also likely enhanced her rapport with interview subjects and enabled her to achieve the depth of understanding critical to good ethnographic work.

Three primary data collection tools were utilized in this study: participation observation, informal interviews, and in-depth semi-structured interviews. Fieldwork mainly took place at the main locale for CCC, a building adjacent the campus of ECU. Observations of students occurred at a variety of CCC-related activities, including Friday dinners and Bible study, Sunday worship services, collaborative socials and prayer meetings (sometimes at other churches in the city), and special events such as holiday celebrations (e.g., Thanksgiving dinner and social). The vast majority of informal interviews took place through the aforementioned activities. All observations and informal interviews were recorded as part of keeping formalized field notes.

Additionally, eight in-depth semi-structured interviews were conducted and all were digitally recorded and transcribed verbatim (they tended to last 45-60 min). These interviews tended to last 45-60 min and all but one were conducted in Chinese. The interview protocol was comprised of several parts, including the following key sections: (a) basic demographic background (including any religious experience prior to coming to the U.S.); (b) reasons for studying abroad; (c) challenges relating to cultural adjustment to ECU and the United States: and (d) experiences and interpretations relating to involvement in CCC.

Of the eight interview subjects, five had formally converted to Christianity and were baptized at CCC. In terms of providing background information about the interview subjects, it is necessary to present such information at the group level, as providing information at the individual level would likely compromise their anonymity and violate IRB policy governing this study. Seven of the subjects were from mainland China, while one was from Taiwan. In terms of gender, four were female and four were male. Seven were undergraduates and one recently started graduate studies. Their average age was 22.5 years old. The students majored in the 
following subjects: accounting, biology, chemistry, composition, geography, communication, management, music.

In terms of the data analysis, we developed a coding scheme that initially included 12 "primary codes," including globalization / internationalization (deriving from study abroad questions), American culture, Chinese culture, CCC activities/events, motivation for participating in $\mathrm{CCC}$, and $\mathrm{CCC}$ relationships, among others. Although these primary codes largely derive from the kinds of questions asked during the interviews and in this sense are deductively generated by the nature of the study, other "secondary codes" emerged after grouping data pieces (interview comments) under the initial primary codes; this may be considered the more inductive phase of the data analysis. An example here are the various kinds of activities and/or events (minor codes) students mentioned that were ultimately listed under "CCC activities/events" (major code). Analyses of the primary and secondary codes resulted in identifying key patterns that helped to address the research questions, and ultimately formed the structure of the following findings section.

\section{RESULTS}

The findings are organized around four primary themes: (a) students' reasons for studying abroad, including their explanations of the perceived benefits of studying in the U.S.; (b) cultural adjustment and perceptions of institutional support; (c) perceived benefits of participating in $\mathrm{CCC}$; and (d) experiencing American culture through CCC.

\section{Reasons for Studying Abroad}

Students' explanations for why they chose to study abroad particularly in the United States resonated with the globalization literature concerning the benefits of exposure and experience in another cultural context. Some students in fact noted the global facets of American society, seeing it as quite positive in terms of wanting to study there. Bainan (all names for students are pseudonyms) explained it this way: "The U.S. is a country of immigrants. It has more cultural diversity [than China]. People can find their own group here in the U.S." And Jia also spoke about the cultural diversity of American society and the benefits of having such experiences: "I wanted to experience a different culture....In the beginning I wanted to go to the U.K., but I in the end after learning more about these two countries, I felt like American society was more diverse." 
Students also highlighted the growing reality of a global higher education market place that in many ways situated U.S. higher education in advantageous positions to that found in their homeland. Amos noted that while China has a handful of superior universities, such as Peking and Tsinghua, the mid-level universities cannot compare to those in the U.S. Coming to the U.S. to study was simply the trend among many of his friends and so chose to as well. Yuqi also believed U.S. university to be more rigorous than that in China, offering the following: "The other reason for studying abroad is the quality of education. The United States has better quality. China's higher education is not so great....In China, when students get to the college stage, they slow down their pace in terms of school work; they don't have to work very hard. However, U.S. students have to work hard in college." Actually, there is a common saying among college students in China: "We had to work so hard in high school just to get into college, that by the time we get to college we feel we deserve a vacation." This may in part explain why a few of the students described undergraduate education in China as somewhat "lax" or "lacking rigor."

Some students noted the advantages of studying in the U.S. in terms of career possibilities. For example, Yuqi commented that, "I finally decided to go to U.S. because it has a bigger market [relative to his field] and it has good diplomatic relations with China. By broader market, I mean it provides more opportunities for Chinese people." Another student, Chanyu, felt there would be more opportunities in the U.S., a belief echoed by her father. Chanyu also felt that studying in the U.S. offered her greater freedom in terms of pursuing her passion, whereas in China she felt great pressure to pursue a career with the "most earnings in the future." As she stated, "Here, I feel can enjoy my major, pursue my passion without worrying about what my future will be with a degree in creative and professional writing. I feel like many students, many people in U.S. pursue their passion. It makes me feel good." Zhiming expressed a similar point: "So here in the U.S., I can express what I'm really interested in...because the only thing I love right now is science."

\section{Cultural Adjustment and Perceptions of Institutional Support}

Despite perceptions by several students that the U.S. seemed like the "land of opportunity," especially initially in making their decisions to study abroad, the actual lived experience of some students did not quite match their original perceptions. Jia elaborated on this: 
"I have always had this feeling that U.S. society is mean to foreigners and people like us who are on an F1 visa. Maybe I cannot say they are racist, but I would put it this way: I think American people and American society are really exclusionary. Although people tend to say that the U.S. is an open society, but in terms of concrete support for international students it is really rare."

Related to the preceding concern, several students expressed apprehension about the limited interactions between international students, including Chinese students, and American students. For example, Zhiming noted complaints about the lack of interaction among ECU's international students and U.S. students: "I have heard a lot of complaints from international students about how they don't have enough chances to speak English with people. But there are two sides to this: You could say that American students are not approaching the international students or that the international students don't really open themselves up to American students."

There was also a perception that ECU did not do enough to help Chinese students adjust to their new surroundings as well as connect with American students. Yuqi explained that while he has a wide range of interesting courses to take as part of his major, "In terms of Chinese social groups, there is space for improvement...the university could do more." He then added, "I mean, for example, a lot of the activities these groups organize do not seem to be attractive enough for Chinese students.... lot students don't want to go to these events." Bainan noted that even though ECU "has a very diverse student population," it "does not provide enough social and academic support." A third student, Zhiming, also expressed criticism of the social support system at ECU. He noted that although there are "a lot of clubs" at ECU, not enough effort is made to reach out to international students in general and Chinese students in particular. $\mathrm{He}$ wondered if this might be because ECU is an urban school, and perhaps staff think students can find enough to do in the city. "I don't really think [ECU] is doing a good enough job to reach international students...they are doing things, but are not doing a good job."

Some students though did not see helping Chinese students to adjust to their new surroundings as ECU's responsibility but instead believed Chinese students needed to take the initiative. As Chanyu explained, "I think there are enough resources at the university. The key is that it all depends on whether you want to make full use of the resources. If you don't approach these resources and get involved, then it seems like there is no support no 
matter how much there is." But Chanyu's take was contrary to the dominant perception that ECU could do much more to support Chinese students, particularly in terms of social support. Perhaps Bainan said it best when he pointed out that because Chinese students pay such high tuition and eventually face the reality that they likely cannot stay in the U.S., "It gives you the feeling that you paid a lot money for not so much in return."

\section{Perceived Benefits of Participating in CCC}

A primary focus of this study was to explore the benefits students associated with participation in CCC. These ranged from basic needs such as food and friendship to high-level self-actualization needs such as spiritual development. For example, nearly every student mentioned how much they appreciated the great meals - particularly Chinese food-prepared and offer by CCC during social events aimed at serving ECU's Chinese students. Meidi noted that "food is the main reason" for first attending a CCC event. And Lin found herself eating at CCC with several of her friends after a particularly busy day in which the food offered was not only convenient but reminded them of home.

During observations, we found that having dinner together is such an established routine at CCC and is general knowledge among many Chinese students at the university. There are clear routines as well: Dinner always starts at $7 \mathrm{pm}$ whether people show up or not and always begins with a prayer. Also, among CCC's volunteers there are clear role expectations as to who cooks and prepares the dinner, who serves dinner, and who cleans up afterwards. The dinner is in some ways the marketing mechanism to an array of important church rituals, as captured by one of the CCC's organizers: "Welcome to [CCC] brothers and sisters. Tonight is a great opportunity for us to get together, sing choir, have some Chinese dishes, and also meet some new friends." Given some of the home sickness, cultural adjustment, and even missing Chinese cuisine, one can imagine how appealing such an event is to ECU's Chinese population. As Gang explained, it's a chance "just to sit together and chat, eat, and talk about what has been going on recently. You know, just catch up with each other." Chanyu added similar comments, "When I can have authentic Chinese food at the church, I feel I am at home. And the elder people at the church are like your aunt and your uncle taking care of you."

Fun and recreation are seen as additional benefits to participation in CCC. Because of the timing of church events are always at the end of the week, normally on Fridays and Sundays, many students have free time on 
these days and are looking for something to do socially speaking. The CCC thus offers a place for them to hang out and have fun while relaxing with other Chinese students. Lin explained it this way: "You know, a busy week is over, and the weekend is coming. That feels good...[CCC] is a place for me to relax and have fun. There are many Chinese people on the weekends. I can speak Chinese and it's relaxing.

Of course, spending time with friends as well as making new friends was one of the key benefits to participating in CCC activities. The following comments from Gang and Lin, respectively, speak to this type of benefit associated with CCC participation: "Going to [CCC] definitely extended my social network a little bit...most of my friends now are from the church, I met them at the church." And, "I would say half of my social network is church people." There was some contradiction here though and at least one student saw the social networks related to CCC as somewhat limiting: "But I think church is not a good place to extend your social network. People who go to the church are always the same."

A key benefit of course to attending $\mathrm{CCC}$ relates to a deeper more religious rationale, including one's personal spiritual development. Students voicing such benefits tended to be the more religiously serious students, some of whom were baptized as Christians at one time or another. For those who already converted to Christianity, such as Gang and Meidi, the benefits of participating in church-related events, of course, were religious in nature and related to worshiping God. Gang offered some insight here: "Going to church is a time when Christians worship God. As a Christian, I am supposed to go." And Meidi added, "Sundays are a time to worship God. I am a Christian, so I need to use that time to worship." These students, and a couple others, spike of "internal peace" and the feeling of being "purified" when communicating to God at CCC. These students tended to be regulars at $\mathrm{CCC}$, having participated in church-related activities for at least a year or more.

\section{Experiencing American Culture through CCC}

Most of the students who participated in interviews as well as many who we chatted with informally spoke of their desire to become acculturated to American society. These same students expressed the point of view that CCC helped to accelerate their cultural adjustment to the broader U.S. society. The fact that CCC offers activities and events reflecting American holidays and customs, such as Thanksgiving dinner, the Chinese students believe participating in CCC allows them to gain exposure to American 
people and their life style; they also often mentioned the chance to speak with Americans using English (a contrary view here is that the Chinese students also noted how relaxing it was to be able to speak Chinese with other Chinese students at CCC).

Some CCC events are held in collaboration with other Philadelphia churches, further exposing the Chinese students to an array of religious organizations and churchgoers, including some predominantly Black and White churches. This appealed to Lin in particular and she discussed this sort of exposure to U.S. culture: "I also wanted to feel and experience American culture. I thought it was new [a collaborative church meeting], I was curious." Meidi also offered similar comments, noting that she just "wanted to practice her English with American people."

Many of the Chinese students consider their participation in CCC as gaining further exposure to American culture through their association of Christianity with "Americaness." Some even noted wanting to learn American history through Bible study. Although one might think that this is somewhat of an odd point, given that Christian scripture pre-dates the founding of the U.S. by nearly two centuries, the reality is that Bible study leaders often connected their Biblical lessons to current issues in the U.S., such as when one teacher noted that scripture does not support homosexuality. To make her point, the Bible study leader shared the Adam and Eve story, using it to emphasize that Christianity supports heterosexual marriages, and that homosexual relationships are not the will of God. Shortly thereafter, advice was offered to female students regarding their clothing style, suggesting that they should "always check your dress," and that "some brothers have complained that some sisters dress too revealing sometimes and it is so hard not to be tempted" (paraphrased based on field notes).

Most students appreciated the opportunity to learn about the U.S. through Bible studies as well as through sermons. As Lin noted, "I thought Christianity is very popular...in the U.S., and so I wanted to feel and experience American culture in this way. I thought it was new and I was curious." And Meidi specifically noted Bible study: "Bible study was very interesting. It is like listening to stories. And sometimes it's interesting to hear people talk about stories and make allusions to daily life...I'd rather listen to these things from the perspective of a Christian church. That is more authentic." 


\section{DISCUSSION AND CONCLUSION}

The cultural and social context that ECU's Chinese international students are embedded in exerts a big pull on their involvement in CCC and church-related activities. The students' desire to expand their knowledge and understanding of U.S. culture was a key factor in choosing to participate in CCC. Also, due to a lack of abundant social networks and university programming targeting the needs of the Chinese international population, combined with their lack of familiarity with where to go for fun and social support, the students in our study turned to an organization that directly targeted their needs and created a space resembling the closest thing to home at ECU. Further, several indicated little interest initially in attending church, noting that were they at a Chinese university, even if church attendance was a possibility, they would be unlikely to participate; but given their new surroundings and missing their home culture (including Chinese cuisine), $\mathrm{CCC}$ helped to fill a major void in their lives, including a spiritual void for a few research participants.

The broader social and cultural context is a key factor in previous research of Chinese conversion to Christianity, with both Yang (1998) and Hall (2006) pointing to factors such as political and cultural turmoil in their homeland as influences in Chinese immigrants' conversion to Christianity. However, the Chinese international students in our study are likely to have grown up in a different environment, one with greater political and cultural stability. Additionally, none of the students when discussing their reasons for participating in CCC suggested that their participation had anything to do with their experiences back home. Instead, the students' reasons were more tied to their new experiences in the United States and at ECU and needs that they believed CCC could help to meet, including advancing their understanding of American culture.

The students consistently discussed their participation in CCC as a means of assimilating into American society by strengthening their knowledge of Christianity and their exposure to church-related social networks. The finding here tends to align well with Yang's (1998) idea that immigrant involvement with Christian churches is seen as a way to assimilate more quickly to the dominant culture of the host society. Cadge and Ecklund (2007) supported this argument as well. The Chinese students at ECU, like subjects in the studies by Yang and Cadge and Ecklund, tend to associate Christianity with mainstream American culture. This point is verified by data we collected in that nearly all the interview participants 
commented that they simply wanted to experience American culture by attending $\mathrm{CCC}$ and related events.

A problem arises, however, in that although ECU's Chinese students see CCC and its teachings as deepening their understanding of American culture, they appear to have limited recognition that CCC in fact represents a subculture within American society, one that at times exists in opposition to the liberal and progressive values of ECU. The culture these Chinese students believe they are getting exposure to at CCC is far from mainstream American culture, given the fact that CCC is a conservative, evangelical Christian church constituting only a small portion of the broader Christian and Protestant churches in the United States; further, CCC also tends to be more conservative than other university-affiliated churches, which typically are influenced by the liberalizing effect of U.S. university life. The conservative characteristics of CCC were partially revealed through our study, as evidenced by some of the Bible study conversations in which homosexuality was disparaged and female members of the CCC community were scolded for wearing revealing clothing.

Some of the values embraced at CCC may impede Chinese international students when they encounter other types of social settings and institutions. For example, ECU is a progressive research university and incorporates a strong diversity agenda into its operations and student support systems. Included in its work with students is a strong commitment to lesbian, gay, bisexual, queer, and transgendered (LGBQT) students. Yet, Chinese students involved in CCC programs and activities are likely to be presented with negative messages about the role of homosexuals in U.S. society. Such exposure may in fact undermine the acculturation of these Chinese students in that were they to enact behaviors on campus consistent with the values of CCC regarding LGBQT students, their actions could in fact have serious ramifications. Further, negative attitudes toward diversity are inconsistent with the progressive educational orientation of ECU and its own potential contributions to Chinese international student acculturation.

It is important to note that none of the students in our interviews or as part of the extensive participant observation expressed any concerns about the conservative values promoted by CCC. Again, they appeared to be under the conviction that $\mathrm{CCC}$ reflects mainstream American culture. This seems especially problematic when considering the fact that the United States is very much a multicultural society, and that many social groups and organizations display values and beliefs quite different from those revealed at CCC. Although the criticism here is not intended to devalue the important spiritual role CCC plays in the lives of the students in our study, it 
nonetheless raises important considerations that host U.S. universities ought to consider.

\section{IMPLICATIONS}

Students in this study pointed to the limited support structure of ECU for Chinese internationals. It seems as though ECU's out-of-class curriculum may be lacking in serving the needs of Chinese students, this despite them paying high tuition and fees. The result in part has been their turn to CCC, which clearly makes the needs of Chinese international students central to its mission. In light of the potential for Chinese student involvement in CCC to undermine the diversity mission of the university, ECU would be wise to invest a little more time, money, and staffing toward meeting the needs of Chinese internationals. Furthermore, with globalization as such a dominant trend, it only seems likely that greater numbers of Chinese internationals will find themselves studying at universities such as ECU. Thus, helping them to acculturate in a manner consistent with the progressive values of U.S. university life seems appropriate.

\section{REFERENCES}

Altbach, P. G. (2003). Globalization and the university: Myths and realities in an unequal world. Current Issues in Catholic Higher Education, 23, 5-25.

Arrighi, G. (2010). The long twentieth century: Money, power, and the origins of our times (2nd ed.). London: Verso.

Babbie, R. E. (2010). The practice of social research (12th ed). Belmont, CA: Wadsworth Cengage.

Blumer, H. (1969). Symbolic interactionism: Perspective and method. Englewood Cliffs, NJ: Prentice-Hall.

Buenker, J. D., \& Ratner, L. A. (2005). Multiculturalism in the United States: A comparative guide to acculturation and ethnicity. Westport, CT: Greenwood Publishing.

Cadge, W., \& Ecklund, E. H. (2007). Immigration and religion. Annual Review of Sociology, 33, 359-379.

Cao, N. (2005). The church as a surrogate family for working class immigrant Chinese youth: An ethnography of segmented assimilation. Sociology of Religion, 66(2), 183-200.

Chong, H. K. (1998). What it means to be Christian: The role of religion in the construction of ethnic identity and boundary among second-generation Korean Americans. Sociology of Religion, 59(3), 259-286.

Giddens, A. (1990). The consequences of modernity. Stanford, CA: Stanford University Press.

Gold, R. L. (1997). The ethnographic method in sociology. Qualitative Inquiry, 
3(4), 388-402.

Hall, B. (2006). Social and cultural contexts in conversion to Christianity among Chinese American college students. Sociology of Religion, 67(2), 131-147.

Held, D. (1991). Editor's introduction.” In D. Held (Ed.), Political Theory Today (pp. 1-22). Stanford: Stanford University Press.

Hurh, W. M., \& Kim, K. C. (1990). Religious participation of Korean immigrants in the United States. Journal for the Scientific Study of Religion, 29(1), 1934.

Jordan, M. (2015, March 24). International students stream into U.S. colleges. The Wall Street Journal. Retrieved from https://www.wsj.com/articles/ international-students-stream-into-u-s-colleges-1427248801

Kalir, B. (2009). Finding Jesus in the holy land and taking him to China: Chinese temporary migrant workers in Israel converting to evangelical Christianity. Sociology of Religion, 70(2), 130-156.

Kang, T. S. (1971). Name change and acculturation: Chinese students on an American campus. The Pacific Sociological Review, 14(4), 403-412.

Luke, A. \& Luke, C. (2000). A situated perspective on cultural globalization. In N.

C. Burbules \& C. A. Torres (Eds.), Globalization and education: Critical perspectives (pp. 275-297). New York: Routledge.

Marden, C. F. \& Meyer, G. (1968). Minorities in America (3rd ed.). New York: Van Nostrand Reinhold.

Polanyi, K. (2001). The great transformation: The political and economic origins of our time (2nd ed.). Boston: Beacon.

Rhoads, R. A., \& Szelényi, K. (2011). Global citizenship and the university: Advancing social life and relations in an interdependent world. Stanford, CA: Stanford University Press.

Ruiz, N. G. (2014). The geography of foreign students in U.S. higher education: Origins and destinations [Research Report]. Washington, DC: Brookings Institute. http://www.brookings.edu/research

Sassen, S. (1991). The global city: New York, London, Tokyo. Princeton: Princeton University Press.

Shirpak, K. R., Maticka-Tyndale, E., \& Chinichian, M. (2007). Iranian immigrants' perceptions of sexuality in Canada: A symbolic interactionist approach. The Canadian Journal of Human Sexuality, 16(3-4), 113-128.

Slaughter, S., \& Rhoades, G. (2004). Academic capitalism and the new economy: Markets, state and higher education. Baltimore: Johns Hopkins University Press.

Smith, R. C. (2006). Mexican New York. Berkeley: University of California Press.

Thomas, W. I., \& Thomas, D. S. (1928). The child in America: Behavior problems and programs. New York: Knopf.

Thomas, W. I., \& Znaniecki, F. (1919). The Polish peasant in Europe and America: Monograph of an immigrant group. Chicago: University of Chicago Press.

Wang, Y., \& Yang, F. (2006). More than evangelical and ethnic: The ecological factor in Chinese conversion to Christianity in the United States. Sociology 
of Religion, 67(2), 179-192.

Wallerstein, I. (2004). World systems analysis. Durham, NC: Duke University Press.

Williams, R. R. (2013). Constructing a calling: The case of evangelical Christian international students in the United States. Sociology of Religion, 74(2), 254-280.

Yang, F. (1998). Chinese conversion to evangelical Christianity: The importance of social and cultural contexts. Sociology of Religion, 59(3), 237-257

Yang, F., \& Tamney, J. B. (2006). Exploring mass conversion to Christianity among the Chinese: An introduction. Sociology of Religion, 67(2), 125129.

XIAOYANG SUN is a Ph.D. candidate in sociology at Temple University in Philadelphia. Her research focuses on ethnic and racial minorities and their experiences in higher education.

ROBERT RHOADS is Professor of Higher Education and Organizational Change and Chinese Studies at the University of California Los Angeles (UCLA). His research focuses on globalization and university reform in China and the United States. 